\title{
О.И. Ивонина
}

\section{КОНЦЕПЦИЯ НОВОГО СРЕДНЕВЕКОВЬЯ Н.А. БЕРДЯЕВА}

\begin{abstract}
В статье исследуется эволюция концепции Нового Средневековья Н.А. Бердяева, отразившей его размышления о путях развития всемирной истории и судьбах европейской культуры. Сделан вывод об экзистенциальном характере историософского дискурса русского мыслителя, чей личный опыт переживаний мировых войн и революций нашел отражение в концепции Нового Средневековья как переходной эпохи, завершающей историю Нового времени.

Ключевые слова: философия истории Н.А. Бердяева; Новое Средневековье; «новое варварство»; христианский универсализм; либеральный социализм.
\end{abstract}

Б.Г. Могильницкий как ученый и учитель обладал талантом соединения энциклопедической эрудиции, профессиональной интуиции и глубочайшей рефлексии над тайнами «ремесла историка». Это качество делало предметом его исследований как отдельных историков, так и различные школы и направления, отразившие в своем творчестве ведущие тенденции развития отечественной и зарубежной интеллектуальной истории.

Интерес самого Б.Г. Могильницкого к творчеству Н.А. Бердяева определялся как традиционной, так и новой проблематикой Томской историографической школы. Отталкиваясь от понимания предмета историографии как истории исторической мысли в различных контекстах и условиях ее развития, он считал Бердяева наиболее ярким представителем и продолжателем традиции русской религиозной философии истории, создателями которой были П.Я. Чаадаев, А.С. Хомяков, И.В. Киреевский, В.С. Соловьев [1. С. 94].

Характерной чертой этого течения следует считать способность к созданию глобальных исторических нарративов для выявления базовых трендов и закономерностей социально-политического и культурного развития, понимания «духа времени» посредством создания ярких исторических образов различных эпох - Античности, Средневековья, Модерна и Современности.

Б.Г. Могильницкий отмечал особую роль Бердяева в изучении архетипов и структур национального характера и исторического сознания, вехами формирования которых становились войны, революции и другие значимые исторические события. Неустранимость именно такого - событийного, политически и эмоционально окрашенного - исторического нарратива как ядра исторической памяти народа требовала от его создателя «волнующего рассказа» о событиях прошлого как владения новейшими методиками исследования исторической памяти, так и литературного мастерства в обработке его результатов [2. С. 23]. Так, своей «ментальной» интерпретацией Русской революции 1917 г. и созданного ею «Нового мира» Н.А. Бердяев, по мнению Б.Г. Могильницкого, составил исторический портрет российской цивилизации - более убедительный, чем соответствующие разделы работ профессиональных историков [1. С. 97-105].

В данной статье предпринята попытка анализа исторической концепции Нового Средневековья Н.А. Бердяева, преемственно связанной с его размышлениями о судьбах русской и мировой истории с позиций междисциплинарного синтеза. Характерными чертами такой исследовательской практики Б.Г. Могильницкий считал органическую взаимосвязь мировоззренческих установок, исторического и идейно-политического контекста, методологического арсенала и проблематики конкретноисторических исследований [3. С. 24].

Николай Александрович Бердяев (1874-1948) был одним из немногих русских мыслителей, чье творчество получило европейское и мировое признание. По свидетельству Н. Полторацкого, в его лице русская мысль вышла на мировую сцену, демонстрируя стремление к всеохватному и целостному мировоззрению, «в котором все его планы - религиозный, философский, культурный, политический, социальный взаимно перекрывались» [4. С. 174].

Фундаментом мировоззренческих установок Бердяева была христианская философия истории. Она определила вектор размышлений Н.А. Бердяева, современника эпохи «великих перемен и разрывов», о судьбах культур и мировой цивилизации, смысле исторического бытия человека и человечества. «Верующий разум» автора сформировал особый подход и оценочный масштаб изучения им проблем отечественной и всемирной истории - «с точки зрения вечности» - Sub specie aeternitatis (одноименное название его работы 1907 г.).

Представления Бердяева о направленности исторического развития народов, производные от понимания христианства как «революционной религии свободы», выражались категорией Богочеловечества. Пониманием всемирной истории как сотворчества Бога и человека русский мыслитель создал новую интерпретацию христианства как мессианско-эсхатологической и вместе с тем предельно гуманистической религии, воплотившей в себе великую правду истории и личной судьбы человека; религии, призванной освободить челове- 
чество от всех уз природного и социального рабства [5. C. 85]. Возложив на человека миссию сотрудника Бога в процессе творческого преображения мира, Н.А. Бердяев завершил длившееся в течение всего XIX в. в русской религиозной мысли превращение христианства из консервативно-охранительной в критическую и освободительную доктрину.

В мировоззрении Бердяева оригинально сочетались идеи, выступавшие антагонистами у других представителей русского религиозного Ренессанса. Христианский революционаризм, индивидуализм и либеральный социализм образовали неповторимый идейный облик исторической концепции Н.А. Бердяева. Автор критически оценивал созданный Новым временем мир капитализма, усматривая в его социальном отчуждении и классовых конфликтах противоположность фундаментальным ценностям христианства - братству, любви и милосердию. Итогом критического осмысления истории капиталистической цивилизации стало требование христианского либерального сочиализма, который виделся ему синтезом общества равенства и социальной справедливости, иерархии творческих талантов, духовного лидерства интеллектуальной аристократии [6. С. 99-100].

Творчество Н.А. Бердяева продемонстрировало совмещение базовых историографических доктрин отечественной мысли в лице западничества и славянофильства. Автор считал свою концепцию христианского социализма созвучной идее соборности как единства людей в свободе и любви, впервые сформулированной А.С. Хомяковым [7. С. 160]. Бердяеву была близка интуиция Вл.С. Соловьева о неизбежном сближении и объединении Востока как родины христианства и Запада как апогея христианской культуры в пространстве и времени единой «универсалистической» эпохи [8. С. 100-101].

Присущий творчеству Н.А. Бердяева синтез либерального социализма и философии персонализма объясняет напряженный нравственный тонус его творческих поисков, понимание истории как манифестации свободы и самоопределения человека, поиск смысла бытия отдельной личности, общества, культуры как уникальной индивидуальности, обладающей непреходящей ценностью для всего человечества.

Особый методологический инструментарий автора был производным от его признания человечества универсальным субъектом всемирной истории, свободное творчество которого демонстрирует разнообразные, порой альтернативные, траектории исторической эволюции. По мнению Бердяева, свобода человека проявляется в творчестве, но равным образом и в грехе, отдалении от Бога, падении на дно социальной реальности. Понимание исторического процесса как постоянной борьбы временного и вечного, свободы и необходимости, рождения и гибели культур, смены эпох и периодов определяло интерес Бердяева к изучению переходных этапов развития всемирной истории: эпохи эллинизма, перехода от Античности к Средневековью, конца Нового времени.
Н.А. Бердяев полагал, что именно в кризисные эпохи вектор исторического развития определяется творчеством «сынов свободы» - ярких личностей. Отсюда его интерес к истории восстания личностей против каких-либо авторитетов и закостенелых общественных систем. Он отмечал: «Я остро сознаю, что сочувствую всем великим бунтам истории - бунту Лютера, бунту разума просвещения против авторитета, бунту «природы» у Руссо, бунту французской революции, бунту идеализма против власти объекта, бунту Маркса против капитализма, бунту Белинского против мирового духа и мировой гармонии, анархическому бунту Бакунина, бунту Л. Толстого против истории и цивилизации» [7. С. 63].

Историческое сознание Н.А. Бердяева оказалось созвучным катастрофическому XX в., наполненному революциями и войнами, чудовищным насилием над природой и разумом человека, исходившим из цитадели мирового прогресса. Сформулированная Бердяевым концепция Нового Средневековья отразила переживания им трагических катаклизмов XX в. и предчувствия глобальных угроз развитию человечества. Его предупреждения о гибели национальных культур и девальвации исторической памяти в глобализирующемся мире; торжестве тоталитарных технократических режимов; всеобщем кризисе гуманизма, приближающем конфликт цивилизаций; противостоянии духовной деградации и творчества сформировали новый контекст обсуждения проблемы смысла и направленности мировой истории, до сих пор сохраняющий свою актуальность.

Своеобразие личности и исторического опыта Н.А. Бердяева вместили в себя такие его работы, как «Самопознание» (1940), «Конец Европы» (1915), «Судьба России» (1918), «Смысл истории» (1923), «Новое Средневековье» (1924), «О назначении человека» (1931), «Судьба человека в современном мире» (1934), «Истоки и смысл русского коммунизма» (1938).

Их анализ убеждает в том, что размышления о судьбах человека и человечества в пространстве и времени всемирной истории не были простыми конструктами авторских идей. Бердяев утверждал, что всякое мировоззрение является плодом осмысления индивидуального экзистенциального опыта, под которым подразумеваются не житейские впечатления, а переживания духовного подъема и личностного самоопределения в экстремальной ситуации конфликта ценностей. Мыслитель отмечал: «Я всегда думал, что познание есть функция жизни, есть символика духовного опыта и духовного пути... И Платон, и Декарт, и Спиноза, и Кант, и Гегель были конкретные люди и они вкладывали в свою философию свое человеческое, экзистенциальное, хотя бы не хотели в этом сознаться» [7. С. 105].

Драма истории XX в. переживалась Н.А. Бердяевым как факт собственной жизни и результат собственного выбора, как часть внутреннего мира мыслителя. Исторический опыт Бердяева вместил в себя две мировые 
войны, революции и Гражданскую войну в России, вынужденное изгнание из России на знаменитом «философском пароходе», нацистский переворот в Германии, оккупацию Франции, начало холодной войны. Сам Бердяев полагал, что его личный опыт именно благодаря наполненности такого рода драматическими событиями носил экзистенциальный характер, раскрывая нечто универсально значимое для судеб мира и человечества [9. С. 133]. Неслучайно мыслитель считал моральным credo историка абсолютную ответственность человека-микрокосма за все исторические события, даже находящиеся вне его контроля и времени жизни.

Концепция всемирной истории Н.А. Бердяева была европоцентристской. Он полагал, что Европа представляет собой единство культур, продемонстрировавших наивысший уровень теофании / богопознания. Глобальная спираль духовной эволюции человечества прослеживалась Бердяевым на материале европейской истории, включившей в себя все этапы мирового развития. Античность породила «всенародную религиозную культуру» и в эпоху эллинизма поставила вопрос о синтезе Запада и Востока, идеально соединив их в фигуре Богочеловека; Средневековье сформировало идеал Царства Божьего; Ренессанс осознал ценность свободы человека; эпоха Нового времени обеспечила рост благосостояния и экономически объединила человечество на основе массового производства и общего международного права. Интерпретация христианства как религии свободы и прогресса определила смысл и вектор исторического развития Запада (стран Европы и Северной Америки). История Запада демонстрировала присущий ей динамизм, формирование единой системы общечеловеческих ценностей на основе социализации базовых принципов христианства - свободы, равенства прав, гуманизма и справедливости.

Однако уже с конца XIX в. Н.А. Бердяев усматривает признаки декаданса исчерпанности творческого потенциала секуляризованной культуры Запада, ее трансформации в технократическую цивилизацию. В работах послевоенного периода мыслитель выносит уже безоговорочный приговор «старому миру новой истории» с его рационалистическим просвещением, индивидуализмом и гуманизмом, либерализмом и демократизмом, с его империалистической политикой, с «чудовищной индустриально-капиталистической системой хозяйства, с его могущественной техникой и внешними завоеваниями и успехами, с безудержной и безграничной похотью жизни, с его безбожием и бездушием, с разъяренной борьбой классов и социализмом как увенчанием всего пути новой истории» [10. С. 412].

По аналогии с эпохой гибели античного мира период всемирной истории, начало которому положила Первая мировая война, Бердяев именует рождением нового неведомого мира эпохой Нового Средневековья. Эта историческая катастрофа была воспринята русским мыслителем как символ «заката Европы» и окончания эпохи Нового времени, в которой Западу принадлежала роль лидера и эталона мирового развития. Н.А. Бердяев, подобно множеству других представителей русской революционной демократии (Г.В. Плеханову, А.А. Богданову, В.И. Ленину), указывал на фактическую, культурно-антропологическую и социально-психологическую обусловленность Первой мировой войны вступлением человечества в новый этап развития - эпоху империализма.

Феномен империализма (как политики и мировоззрения) демонстрировал, по мнению Бердяева, разрыв Запада с базовыми, религиозно обоснованными ценностями, доселе предлагаемыми миру в качестве универсальных образцов «цивилизованности» и прогресса: гуманизма, гражданских прав и свобод человека, самоопределения народов и национально-государственного суверенитета, неукоснительного соблюдения норм международного права.

Н.А. Бердяев писал: «Империализм - техническое порождение цивилизации. Империализм не есть культура. Он есть оголенная воля к мировому могуществу, к мировой организации жизни» [5. С. 172]. Империализм, по его мнению, есть симптом новой исторической эпохи, которую автор назвал «концом Европы». По утверждению мыслителя, «империализм с его колониальной политикой есть современный, буржуазный способ расширения цивилизации за пределы Европы ...Современный империализм - явление чисто европейское, но он несет с собой энергию, окончательное раскрытие которой означает конец Европы» [11. С. 117].

Эпоха империализма завершает некогда устойчивую географическую ориентацию мирового исторического процесса. Мировая история, двигавшаяся с Востока на Запад, начинает обратное движение, и империализм является орудием такого поворота. По словам Н.А. Бердяева, «...обратное движение с Запада на Восток, повидимому, является внутренне неизбежной диалектикой европейской культуры... Империализм с его колониальной политикой есть одно из внешних выражений этого неотвратимого движения истории» [Там же. С. 125].

Мир движется к новому историческому объединению, однако, по мнению философа, это не будет повторением культурного синтеза, некогда отличавшего движение истории с Востока на Запад и создавшего феномен эллинизма и римского универсализма. Европе нечего дать Востоку в сфере духа. Ее собственная рационалистическая культура - в кризисе. Восток - это «внешнее варварство» и угроза для европейской культуры: «Извне же грозит европейской христианской культуре монгольский Восток, имеющий свою антихристианскую идею, свою враждебную нам и непонятную нам цивилизацию» [Там же. С. 225].

Неизбежная универсализация мира виделась Н.А. Бердяеву в трагическом свете, чередой столкновений культур. Глобальный военный конфликт, инициатором которого стали «цивилизованные» народы Европы, опрокинул мир в эпоху «Нового варварства». Ее символами стали для Бердяева культ техники, марги- 
нализация и атомизация общества, милитаризация сознания и поведенческих стандартов населения, тотальная манипуляция массовым сознанием, внеэкономические методы принуждения, мобилизационный тип экономики, кризис либеральной демократии [10. С. 417].

Н.А. Бердяев считал конец новой истории и начало Нового Средневековья финалом не только событийной, но и интеллектуальной истории Запада. Время «обнажений и разоблачений» доказало, что самосознание человека Нового времени как эпохи освобождения из плена сословно-корпоративных и конфессиональных ограничений, внеэкономического принуждения и подчинения властным авторитетам было иллюзией. В эпоху господства техники, демократии, общественного мнения, прессы и парламентаризма появились, по мнению философа, лишь новые формы зависимости человека от общества, новые, более действенные, чем прежде, формы контроля, которые способствуют утрате индивидуальности, национально-культурной самобытности, всеобщей стандартизации и унификации [Там же. С. 416].

Не только светская культура Европы казалась Бердяеву непрочной. Он отверг наличие и той духовной христианской «почвы», на которой основывалась гуманистическая культура Европы, значение которой столь высоко ценилось даже позитивистской историографией. Русский автор не обнаружил в современной ему Европе следов вековой христианизации, которая прежде казалась неустранимой основой западной культуры. Теперь воздействие христианства на массовое сознание и культуру народов представлялось ему поверхностным, не затронувшим глубинных слоев европейской жизни. Наиболее неблагополучной виделась в этом отношении Центральная Европа, в первую очередь, Германия. Автор писал: «Ни расизм, ни антисемитизм не есть нечто неожиданное в Германии, это старая болезнь германского духа, свидетельствующая о том, что христианство недостаточно переработало и преобразило глубинный слой германского язычества» [12. С. 350].

Впечатления от Первой мировой войны оказались у Н.А. Бердяева настолько сильными, что он всю оставшуюся жизнь считал ее системообразующим фактором всей Новейшей истории. События всемирной истории после 1914 г. представлялись ему лишь продолжением этой катастрофы. Послевоенное развитие мира, в котором усиливались авторитарные, коммунистические и национал-социалистические движения, Н.А. Бердяев оценивал с позиций своего исторического метапессимизма. В книге, написанной во второй половине 40-х гг., мыслитель признавал: «Мы живем в мире, созданном двумя мировыми войнами, и готовимся к третьей мировой войне. Мы живем в мире, в котором революция является лишь трансформацией войны. Это определяет все ценности» [13. С. 323].

Н.А. Бердяев указывал на неадекватность прежней, детерминистской исторической методологии для понимания современного этапа всемирной истории, слишком непохожего на мир прошлого. Позитивист- ский историзм казался русскому автору достоянием благополучного XIX в., отразившим его философию времени и интеллектуальную атмосферу. Первая мировая война опровергла то, что казалось незыблемым приобретением человечества - прочность культурных устоев комфортной и респектабельной истории Запада. Чудовищный факт мировой бойни, развязанной передовыми европейскими нациями, показал ошибочность фундаментальных тезисов либеральной рационалистической историографии: в истории нет поступательного развития, необратимости достижений культуры и цивилизации. Мировая война сдернула тонкую пленку цивилизации XIX - начала XX в., обнажила глубинные пласты человеческой жизни, расковала хаос иррационального в человеческой природе [12. С. 322].

Ситуацию кризиса прежних объяснительных схем, сконцентрированных на идее прогресса и ценностей гуманизма, философ назвал методологическим «безвременьем». Он утверждал: «Я исхожу из глубокого убеждения в том, что нет возврата ни к тому образу мысли, ни к тому строю жизни, которые господствовали до мировой войны, до революций и потрясений, охвативших не только Россию, но Европу и весь мир. Bсе привычные категории мысли и формы жизни самых “передовых”, “прогрессивных”, даже “революционных” людей XIX и XX веков безнадежно устарели и потеряли всякое значение для настоящего и особенно для будущего» [10. С. 411].

Первая мировая война стала для Н.А. Бердяева подтверждением его прогноза о завершении прежнего, прогрессистского по своей направленности проекта всемирной истории, на смену которому приходит эра неопределенности (столь созвучная понятию расплывающейся, текучей liquid Современности 3. Баумана). Он отмечал: «Нынешнее историческое время подобно эпохе великого переселения народов. Чувствуется, что человечество вступает в новый исторический и даже космический период, в какую-то великую неизвестность, совершенно непредвиденную никакими научными прогнозами, ниспровергающую все доктрины и учения» [11. С. 114].

Переживание событий Второй мировой войны усилило интуицию альтернативности всемирной истории, ранее проявлявшуюся у Бердяева лишь в оценках исторических судеб России. Послевоенная история казалась философу конкуренцией нескольких альтернативных тенденций мирового развития, различных вариантов выхода из кризиса, переживаемого современной цивилизацией: «1. Исход фатальный. Продолжающееся распадение космоса природного и космоса социального, продолжающийся разлагаться капиталистический режим, торжество атомной бомбы, хаотический мир, раскрытый в творчестве Генри Миллера, хаос не изначальный, а хаос конца, война всех против всех... 2. Насильственный, механический порядок коллектива, организованность, не оставляющая места свободе, деспотизация мира... 3. Внутреннее преодоление 
хаоса, победа духа над техникой, духовное восстановление иерархии ценностей, соединенное с осуществлением социальной правды...» [13. С. 323].

Первая альтернатива современного развития проявляется, по мнению философа, в цивилизационной унификации мирового развития. Уже Первая мировая война подтвердила справедливость прогноза как самого Бердяева, так и его оппонентов в лице Ленина и Гильфердинга о расширении капиталистической цивилизации на Восток средствами империалистической экспансии. Для Бердяева эта тенденция свидетельствовала о попятном движении всемирной истории, от окончания зрелого Модерна (капиталистической цивилизации) к началу эпохи Нового Средневековья.

В «Пробуждении Востока», в национальноосвободительных движениях афро-азиатских народов Н.А. Бердяев увидел все то же торжество внутренне исчерпанного Запада, передающего многомилионным народам Индии и Китая самые дурные стороны европейской цивилизации: материализм, национализм, примитивные культурные стандарты массового общества, упоение техническим прогрессом. Заимствованные у европейцев современные технологии Восток, по мнению философа, станет использовать инструментально - в качестве средства противостояния с Западом в экономической и военно-политической сфере, приближая, тем самым, собственное возвышение и «падение Европы» в силу утраты ею роли эталона мирового развития. Мыслителя беспокоил факт активного вовлечения в мировую историю огромных масс, превышающих население Европы, именно в тот момент, когда они усвоили себе самые дурные стороны европейской цивилизации - агрессивный национализм эпохи Ренессанса и Наполеоновских войн [12. С. 355].

Подобно Ортеге-и-Гассету, Н.А. Бердяев считал признаком Нового Средневековья появление масскультуры, порывающей как с традиционными духовными ценностями, так и с исторической традицией народов Востока и Запада. Он отмечал: «Цивилизация через империализм и через социализм должна разлиться по поверхности всей земли, должна двигаться и на Восток. К цивилизации будут приобщены новые массы человеческие, новые слои. И новое средневековье будет цивилизованным варварством, варварством с запахом машин, а не лесов и полей - варварство, заложенное в самой технике цивилизации. Такова диалектика цивилизации» [5. С. 172].

Наряду с мировой цивилизационной унификацией действует и вторая тенденция, отмеченная Н.А. Бердяевым, - тоталитарная револючия, создание принудительно организованных сообществ. Мыслитель считал, что первая и вторая тенденции мирового развития связаны между собой, так как, разрушая культуру, цивилизация взращивает «внутреннее варварство» на своей собственной почве, демонстрируя процесс «огрубления, утраты совершенных форм, некогда выработанных культурой» [5. С. 172].
«Новые варвары», люди массового общества, становятся преобладающей политической силой. Тоталитарная революция, подготовленная буржуазным обществом, оставляет человечество в пределах циивилизации, но меняет социальную форму последней. Буржуазная цивилизация сменяется индустриальной, превращая жизнь миллионов в «огромный и организованный производственный процесс, в промышленную мастерскую, которую должно украшать искусство и обслуживать знание» [14. С. 52].

Н.А. Бердяев был в числе тех, кто считал противостояние с либерализмом и индивидуализмом общим свойством большевизма, фашизма, национал-социализма и прочих версий тоталитаризма XX в. По его мнению, все тоталитарные режимы стремятся к контролю над массовым и индивидуальным сознанием, устраняя свободу даже из мира душевных переживаний личности. Автор утверждал: «Все мышление делается принудительным, подчиняется социальному вероисповедному центру, т.е. происходит возврат к средневековью, но уже не на религиозной, а на материалистической почве» [15. С. 40].

Глубинным сходством тоталитарных режимов мыслитель объяснял их враждебность культуре, демократическим свободам и уважению человеческого достоинства, наглядно проявившиеся в политике России, Германии, Италии. Страна философов и поэтов оказалась в 30-х гг. местом гонения духа: «Германия, в которой раньше был настоящий культ ученых, философов, профессоров, университетов... теперь совершенно перестала уважать ученых, философов, профессоров, университеты и готова их разгромить» [12. С. 341].

Победу тоталитарных тенденций в развитии послевоенного мира Н.А. Бердяев считал разрывом Запада с наследием эпохи гуманизма и Просвещения, аналогично торжеству феодальной реакции в Европе после Наполеоновских войн - «внутренней реакции против всей новой истории, реакции против всего ренессансного освободительного периода и против французской революции» [16. С. 393-394].

Тоталитаризм как форма «нового варварства» обращается к архетипам сознания и переустраивает общество на началах традиционализма и архаического коллективизма. Однако это «вторая редакция» традиционализма, который принимает цивилизованные формы, используя все орудия и блага цивилизации.

Тоталитарное общество доводит до предела инфернальную эсхатологию цивилизации, демонстрируя возможность «повторного варварства» - реакционного восстания маргиналов против достижений мировой и национальной культуры. По мнению Бердяева, это восстание свидетельствует о необратимом регрессе культуры, преобладании попятных и даже тупиковых траекторий всемирной истории. «Новое варварство» в принципе не способно к аккультурации, в отличие от варварских племен эпохи раннего Средневековья. Н.А. Бердяев писал: «...ныне европейской культуре 
грозит напор варварства изнутри и извне. Это почувствовалось уже, когда началась мировая война, и чувство это достигло особенной остроты, когда разыгралась русская революция... Внутренне революционное варварство бурно вступает в культурный мир уже глубоко испорченным лживыми антихристианскими идеями, искаженным рассудочным полупросвещением, с извращенной массовой психологией, с претензиями какой-то ложной полукультуры... Оно само есть продукт безбожной цивилизации, восставшей против высшей культуры» [17. С. 225].

Своеобразие мирового развития после Первой мировой войны Бердяев усматривал в том, что пришедшая в упадок эпоха Новой истории и идущая ей на смену эпоха Нового Средневековья сосуществуют в одном физическом времени, однако территориально размежевавшись. Символом первой эпохи является США, второй - СССР. Конфликт модерна / Новой истории и постмодерна / Нового Средневековья принял вид противостояния ценностей свободы и социальной справедливости. Н.А. Бердяев писал: «Сейчас очень любят противополагать ценность социальной справедливости ценности свободы и предлагают выбирать. Эти основоположные ценности располагают географически: Советская Россия - за социальную справедливость, Америка - за свободу. Поэтому считают неиз- бежным их конфликт. При этом свобода оказалась почти совершенно отождествленной с капитализмом. Против такого рода постановки вопроса нужно всеми силами протестовать» [13. С. 322]. На самом деле, полагал автор, современное буржуазное общество мало благоприятствует свободе, а советское - справедливости.

Параллельно с ужасающими картинами агонии новой истории и погружения в ночь тоталитарного Нового Средневековья Н.А. Бердяев рассуждал о третьей тенденции послевоенного развития - новом духовном возрождении человечества, «новой творческой эпохе». Эту перспективу мирового развития мыслитель связывал с созданием посткапиталистического общества социальной справедливости и всеобщего благоденствия, способного преодолеть прагматизм индустриальной цивилизации и создать новую «всенародную религиозную культуру». Вместе с тем философ не считал тенденцию к духовному возрождению человечества господствующей в силу своей приверженности историческому пессимизму и трагическому пониманию истории человечества. Представляется, что этот вектор всемирной истории был в большей степени предметом упований и надежд религиозного мыслителя, нежели результатом углубленного научного анализа альтернатив послевоенного развития.

\section{ЛИТЕРАТУРА}

1. Могильницкий Б.Г. Русская революция в оценке Н.А. Бердяева // История исторической мысли ХХ века: Курс лекций. Вып. I: Кризис историзма. Томск : Изд-во Том. ун-та, 2001. С. 97-105.

2. Могильницкий Б.Г., Николаева И.Ю., Ким С.Г., Мучник В.М., Карначук Н.В. Историческое познание и историческое сознание // Историческая наука и историческое сознание. Томск : Изд-во Том. ун-та, 2000. 234 с.

3. Могильницкий Б.Г. У истоков Томской историографической школы. А.И. Данилов и проблема преемственности в отечественной историкотеоретической мысли XX века // Методологические и историографические вопросы исторической науки / отв. ред. Б.Г. Могильницкий, И.Ю. Николаева. Томск : Изд-во Том. ун-та, 2007. Вып. 28. С. 5-25.

4. Полторацкий Н. Русская религиозная философия // Мосты. 1960. № 4. С. 172-180.

5. Бердяев Н.А. Смысл истории. М. : Мысль, 1990. 176 с.

6. Бердяев Н.А. Новое религиозное сознание и общественность. СПб. : М.В. Пирожков, 1907. 233 с.

7. Бердяев Н.А. Самопознание. М. : Мысль, 1991. 220 с.

8. Бердяев Н.А. Восток и Запад // Путь. 1930. № 23. С. 97-109.

9. Герцык Е. Воспоминания. Paris : YMCA-Press, 1973. 192 c.

10. Бердяев Н.А. Новое Средневековье // Философия творчества, культуры и искусства. М. : Искусство, 1994. Т. 1. С. $406-464$.

11. Бердяев Н.А. Судьба России. М. : Прометей, 1990. 158 с.

12. Бердяев Н.А. Философия свободного духа. М. : Республика, 1994. 480 с.

13. Бердяев Н.А. Царство Духа и Царство Кесаря. М. : Республика, 1995. 382 с.

14. Бердяев Н.А. Социальный кризис культуры // Новый град. 1932. № 3. С. 46-53.

15. Бердяев Н.А. Конец Ренессанса // София: Проблемы духовной культуры и религиозной философии. Берлин : Обелиск, 1923.270 с.

16. Бердяев Н.А. Конец Ренессанса и кризис гуманизма // Философия творчества, культуры и искусства. М. : Искусство, 1994. Т. 1. С. 392-406.

17. Бердяев Н.А. Философия неравенства // Русское зарубежье. Л. : Лениздат, 1991. 440 с.

Olga I. Ivonina. Novosibirsk State Pedagogical University (Novosibirsk, Russian Federation). E-mail: ivonina@ngs.ru

BERDYAEV'S “NEW MIDDLE AGES" CONCEPT

Keywords: N.A. Berdyaev's philosophy of history; The New Middle Ages; The New Barbarism; The New Creative Era; Christian Universalism; Liberal Socialism.

The purpose of this article is to analyze N.A. Berdyaev's "New middle Ages" conception through the methodology of interdisciplinary synthesis developed by the Tomsk historiographic school led by B.G. Mogilnitsky. This makes N.A. Berdyaev's works a historiographic fact, reflecting the historical context, author's ideological, political and academic preferences, his belonging to a certain course of intellectual history. The main author's objective was to study evolution of Berdyaev's "New Middle Ages" concept, reflecting his thoughts on the world history and European culture fates in the twentieth century.

In result, the author made the following conclusions:

The religious historiosophy was the foundation of N.A. Berdyaev's worldview and historiographic attitudes, determined his assessment of world history's key events, characters and processes. Berdyaev's ideas about Christianity as a "revolutionary religion of freedom" formed his understanding of world history as the co-creation of God and man in the process of transforming the world. Thus, the Russian thinker created a new interpretation of Christianity as a messianic-eschatological and at the same time humanistic religion, embodying the great truth of history and the personal destiny of man, designed to free humanity from all bonds of natural and social slavery. 
The concept of the "New Middle Ages" reflected the existential nature of the historical and political discourse of the Russian thinker, whose personal experience contained the perceptions of two world wars, revolutions in Russia, Europe and Asia, totalitarianism, globalization.

The symbolism of the "New Middle Ages" contained the basic sociocultural and political intentions of the Russian religious Renaissance: Christian humanism, personalism, liberal socialism.

This N.A. Berdyaev's concept also combined two basic Slavophile's and Westernism historiographic doctrines: liberal modernism, Christian universalism and messianism, characteristics of Russian Europeanism as a whole. The synthesis of Christian universalism and liberal socialism has given the "New Middle Ages" concept features of a perspective utopia.

The "New Middle Ages" concept reflected such original N.A. Berdyaev's historiographical constructs as "the end of Europe", "awakening of the East", "the old world of the New Age", "the failure of history", "the era of uncertainty", "new barbarism", "new creative era".

The author believes that Berdyaev's "New Middle Ages" concept was a continuation and creative development of Russian religious Renaissance intellectual tradition with its desire to search a new language of historical narrative towards synthesis of historical comparative studies, historiosophy, psychohistory and cultural anthropology.

\section{REFERENCES}

1. Mogilnitsky, B.G. (2001) Istoriya istoricheskoy mysli XX veka [History of Historical Thought of the Twentieth Century]. Vol. 1. Tomsk: Tomsk State University. pp. 97-105.

2. Mogilnitsky, B.G. (2000) Istoricheskoe poznanie i istoricheskoe soznanie [Historical knowledge and historical consciousness]. In: Mogilnitsky, B.G. et al. Istoricheskaya nauka i istoricheskoe soznanie [Historical science and historical consciousness]. Tomsk: Tomsk State University.

3. Mogilnitsky, B.G. (2007) U istokov Tomskoy istoriograficheskoy shkoly. A.I. Danilov i problema preemstvennosti v otechestvennoy istorikoteoreticheskoy mysli XX veka [At the origins of the Tomsk historiographic school. A.I. Danilov and the problem of continuity in Russian historical and theoretical thought of the 20th century]. In: Mogilnitsky, B.G. \& Nikolaeva, I.Yu. (eds) Metodologicheskie i istoriograficheskie voprosy istoricheskoy nauki [Methodological and historiographic questions of history]. Tomsk: Tomsk State University. pp. 5-25.

4. Poltoratsky, N. (1960) Russkaya religioznaya filosofiya [Russian religious philosophy]. Mosty. 4. pp. 172-180.

5. Berdyaev, N.A. (1990) Smysl istorii [The meaning of history]. Moscow: Mysl'.

6. Berdyaev, N.A. (1907) Novoe religioznoe soznanie i obshchestvennost' ${ }^{\prime}$ New religious consciousness and the public]. St. Petersburg: M.V. Pirozhkov.

7. Berdyaev, N.A. (1991) Samopoznanie [Self-knowledge]. Moscow: Mysl'.

8. Berdyaev, N.A. (1930) Vostok i Zapad [East and West]. Put'. 23. pp. 97-109.

9. Gertsyk, E. (1973) Vospominaniya [Memoirs]. Paris: YMCA-Press.

10. Berdyaev, N.A. (1994a) Filosofiya tvorchestva, kul'tury i iskusstva [The Philosophy of Creativity, Culture and Art]. Vol. 1. Moscow: Iskusstvo. pp. 406-464.

11. Berdyaev, N.A. (1990) Sud'ba Rossii [The Fate of Russia]. Moscow: Prometey.

12. Berdyaev, N.A. (1994) Filosofiya svobodnogo dukha [The Philosophy of Free Spirit]. Moscow: Respublika.

13. Berdyaev, N.A. (1995) Tsarstvo Dukha i Tsarstvo Kesarya [The Kingdom of the Spirit and the Kingdom of Caesar]. Moscow: Respublika.

14. Berdyaev, N.A. (1932) Sotsial'nyy krizis kul'tury [Social crisis of culture]. Novyy grad. 3. pp. 46-53.

15. Berdyaev, N.A. (1923) Sofiya: Problemy dukhovnoy kul'tury i religioznoy filosofii [Sofia: Problems of spiritual culture and religious philosophy]. Berlin: Obelisk.

16. Berdyaev, N.A. (1994c) Filosofiya tvorchestva, kul'tury i iskusstva [The Philosophy of Creativity, Culture and Art]. Vol. 1. Moscow: Iskusstvo. pp. 392-406.

17. Berdyaev, N.A. (1991) Filosofiya neravenstva [The philosophy of inequality]. In: Berdyaev, N.A. \& Frank, S.L. Russkoe zarubezh'e [Russian émigré]. Leningrad: Lenizdat. 